\title{
Acute AT1 receptor blockade does not improve the depressed baroreflex in rats with chronic renal hypertension
}

\author{
V.M.A. Farah, E.D. Moreira, \\ M. U shizima, I.A. Cestari, \\ M.C. Irigoyen and \\ E.M. Krieger
}

Divisão de Experimentação e U nidade de Hipertensão, Instituto do Coração - InCor, Hospital das Clínicas, Faculdade de Medicina, U niversidade de São Paulo, São Paulo, SP, Brasil

\section{Correspondence \\ M.C. Irigoyen \\ Divisão de Experimentação e \\ Unidade de Hipertensão, InCor, USP \\ Av. Dr. Eneas C. Aguiar, 44 \\ 05403-000 São Paulo, SP \\ Brasil \\ Fax: + 55-11-3069-5048 \\ E-mail: hipirigoyen@incor.usp.br \\ Research supported by FAPESP and CNPq.}

Received September 14, 1999 Accepted September 13, 2000

\section{Abstract}

To assess the role of angiotensin II in the sensitivity of the baroreflex control of heart rate $(\mathrm{HR})$ in normotensive rats $(\mathrm{N}=6)$ and chronically hypertensive rats ( $1 \mathrm{~K} 1 \mathrm{C}, 2$ months, $\mathrm{N}=7$ ), reflex changes of $\mathrm{HR}$ were evaluated before and after $(15 \mathrm{~min})$ the administration of a selective angiotensin II receptor antagonist (losartan, $10 \mathrm{mg} / \mathrm{kg}, i v$ ). Baseline values of mean arterial pressure (MAP) were higher in hypertensive rats $(195 \pm 6 \mathrm{mmHg})$ than in normotensive rats $(110 \pm 2 \mathrm{mmHg})$. Losartan administration promoted a decrease in MAP only in hypertensive rats (16\%), with no changes in HR. During the control period, the sensitivity of the bradycardic and tachycardic responses to acute MAP changes were depressed in hypertensive rats $(\sim 70 \%$ and $\sim 65 \%$, respectively) and remained unchanged after losartan administration. Plasma renin activity was similar in the two groups. The present study demonstrates that acute blockade of AT1 receptors with losartan lowers the MAP in chronic renal hypertensive rats without reversal of baroreflex hyposensitivity, suggesting that the impairment of baroreflex control of HR is not dependent on an increased angiotensin II level.

In chronic hypertension, the threshold of the arterial baroreceptors is reset to the high resting arterial pressure, and a significant reduction occurs in arterial baroreceptor gain that could be responsible in part for the impairment of the baroreflex control of heart rate (HR) observed in several forms of chronic hypertension (1-5). In rats with chronic renal hypertension ( $1 \mathrm{~K} 1 \mathrm{C}, 2$ months), the pressure threshold for baroreceptor activation is reset to hypertensive levels and is accompanied by a depressed sensitivity of the arterial baroreceptor afferents (36\%) (6). The impairment of the baroreceptor reflexes has been associated with chronic renin-angiotensin system overactivity (3). The renin-angiotensin system has been involved in the modulation of HR responses in chronic renal hypertension and in the other models of high-renin hypertension $(1,3)$. Angiotensin II has also been shown to centrally modulate the reflex bradycardia of spontaneously hypertensive and normotensive control rats (4), impairing the reflex bradycardia during transient increases in pressure without changing blood pressure levels. Although many studies have reported 
only transient increases in plasma renin activity in the $1 \mathrm{~K} 1 \mathrm{C}$ model of renal hypertension, persistent increases in plasma renin activity may also occur in this model depending on the severity of hypertension (7).

The actions of angiotensin II are mediated by the interactions of this peptide with specific receptors that have been classified into two major types: AT1 and AT2. AT1 receptors have been associated with all of the known cardiovascular and renal effects of angiotensin II (8). Losartan, the first nonpeptide angiotensin II receptor antagonist, exerts its antihypertensive actions through the inhibition of angiotensin II binding to AT1 receptors $(9,10)$. Moreover, losartan crosses the blood-brain barrier in vivo blocking the AT1 receptor in different brain nuclei, including the nucleus tractus solitarius and dorsal motor nucleus of the vagus nerve (11).

The present experiment was undertaken to analyze the sensitivity of the baroreflex control of HR, bradycardia, and tachycardia reflex in male rats with chronic ( 2 months) $1 \mathrm{~K} 1 \mathrm{C}$ renal hypertension $(\mathrm{N}=7)$ during the control period and after acute (15 min) administration of losartan $(10 \mathrm{mg} / \mathrm{kg}, i v)$. On the day before the experiment, catheters were fitted into the rats' right femoral artery and vein for blood pressure measurements and drug injection. To evaluate the baroreflex control of HR, changes in mean arterial pressure (MAP) ( \pm 10 to $\pm 40 \mathrm{mmHg}$ ) were produced by increasing doses of phenylephrine and sodium nitroprusside ( 0.25 to $16 \mu \mathrm{g} / \mathrm{ml})$ administered by bolus injections $(0.1 \mathrm{ml})$ to conscious unrestrained rats. The relationship between changes in arterial pressure and changes in HR was assessed by mean index, linear regression analysis, and by the logistic method (maximum gain of the sigmoid curve by a logistic function), which has the advantage of providing a better comparison of the baroreflex sensitivity of animals with different basal blood pressure levels (12). The mean index of baroreflex sensitiv- ity for each rat was calculated as the mean value of all points $(\triangle \mathrm{HR} / \triangle \mathrm{MAP})$ for the bradycardic responses, and another index was calculated for the tachycardic responses. The regression coefficient (slope) was determined for each rat by fitting a separate linear regression line through the points over a wide range for the bradycardia and tachycardia responses. In the logistic function (sigmoid curve), all data points for the bradycardic and tachycardic responses were plotted after the alterations in blood pressure using a specially developed computer program to fit the logistic function relating MAP to HR (12). The same data points obtained after blood pressure alteration and the corresponding HR alteration were used to calculate the index, the linear regression, and the sigmoid curve. For the plasma renin activity assay, free-flowing blood $(\sim 1 \mathrm{ml})$ was collected from conscious unrestrained rats one day after the end of the experiments. The results are reported as mean $\pm \mathrm{SEM}$, and the Student $t$-test was used to compare groups, with differences considered significant at $\mathrm{P}<0.05$.

The MAP of the hypertensive rats was $195 \pm 6 \mathrm{mmHg}$ compared with $110 \pm 2$ $\mathrm{mmHg}$ for the normotensive control rats $(\mathrm{N}$ $=6$ ). After acute administration of losartan, the MAP of the hypertensive rats decreased significantly to $164 \pm 11 \mathrm{mmHg}$, with no change in HR ( $354 \pm 21$ vs $385 \pm 20 \mathrm{bpm})$. In normotensive rats the MAP after losartan was not significantly different $(104 \pm 5$ $\mathrm{mmHg}$ ), and the HR increased slightly but not significantly ( $373 \pm 20$ vs $324 \pm 12$ bpm) (Figure 1).

During the control period, the baroreflex index (average $\triangle \mathrm{HR} / \triangle \mathrm{MAP}$ ) for the bradycardic responses was reduced in the hypertensive rats, corresponding to $27 \%$ of the values of normotensive rats $(0.4 \pm 0.1$ vs 1.5 $\pm 0.2 \mathrm{bpm} / \mathrm{mmHg}$ ). After losartan, the index of the reflex bradycardia sensitivity remained unchanged in both groups (hypertensive rats: $0.5 \pm 0.1 \mathrm{bpm} / \mathrm{mmHg}$ and normotensive rats: $1.4 \pm 0.2 \mathrm{bpm} / \mathrm{mmHg}$ ). The sensitivity of the 
reflex bradycardia analyzed by linear regression was also depressed in the hypertensive rats $(0.5 \pm 0.1 \mathrm{bpm} / \mathrm{mmHg})$, corresponding to $28 \%$ of the normotensive rat values $(1.8 \pm$ $0.5 \mathrm{bpm} / \mathrm{mmHg}$ ). After losartan, the regression coefficient for bradycardic reflex sensitivity remained unchanged in hypertensive rats $(0.5 \pm 0.2 \mathrm{mmHg})$ and normotensive rats $(1.7 \pm 0.4 \mathrm{bpm} / \mathrm{mmHg})$ (Figure $2 \mathrm{~A})$.

The baroreflex index (average $\Delta \mathrm{HR} /$ $\triangle \mathrm{MAP}$ ) for the tachycardic responses during the control period was depressed in the hypertensive rats $(1.4 \pm 0.5 \mathrm{bpm} / \mathrm{mmHg}) \mathrm{com}$ pared to normotensive rats $(4.0 \pm 0.4 \mathrm{bpm} /$ $\mathrm{mmHg})(35 \%$ of the normotensive rat values). After losartan, the index remained unchanged in both hypertensive and normotensive rats $(2.0 \pm 0.6$ and $3.1 \pm 0.3 \mathrm{bpm} / \mathrm{mmHg}$, respectively). Linear regression analysis showed that the sensitivity of the tachycardic reflex was also depressed in hypertensive rats $(1.9 \pm 0.9 \mathrm{bpm} / \mathrm{mmHg})$ when compared to normotensive rats $(5.1 \pm 1.7 \mathrm{bpm} / \mathrm{mmHg})$ ( $37 \%$ of the normotensive rat values). After losartan, the regression coefficient for the tachycardic reflex remained unchanged in both the hypertensive $(2.6 \pm 1.1 \mathrm{bpm} / \mathrm{mmHg})$ and normotensive rat groups $(3.7 \pm 0.7 \mathrm{bpm} /$ $\mathrm{mmHg}$ ) (Figure 2B).

The average gain in the sensitivity of the baroreflex control of HR during the control period was analyzed by logistic function, which showed depression in hypertensive rats $(2.6 \pm 0.6)$ compared with normotensive rats $(5.6 \pm 0.7)$. After losartan administration, the average gain remained unchanged in both groups $(2.2 \pm 0.5$ in hypertensive rats and $4.0 \pm 0.5$ in normotensive rats) (Figure $2 \mathrm{C}$ ).

Plasma renin activity was measured in the hypertensive rat group $(1.6 \pm 0.4 \mathrm{ng}$ angiotensin $\mathrm{I} / \mathrm{ml}$ ) and was similar to that in normotensive rats $(2.6 \pm 0.7 \mathrm{ng}$ angiotensin $\mathrm{I} /$ $\mathrm{ml}$ ).

The present study demonstrates that acute blockade of AT1 receptors with losartan lowers blood pressure in $1 \mathrm{~K} 1 \mathrm{C}$ hypertensive rats having a normal level of plasma renin activity. Although in this study plasma renin activity was within the range of normal values, a significant increase was observed in aortic and mesenteric angiotensin converting enzyme activity and aortic angiotensin II levels in rats with chronic $1 \mathrm{~K} 1 \mathrm{C}$ hypertension, suggesting that local generation of angiotensin II may be increased in arteries from $1 \mathrm{~K} 1 \mathrm{C}$ hypertensive rats. In addition, an angiotensin converting enzyme inhibitor, enalapril, acutely administered intravenously to unanesthetized rats, significantly lowered the blood pressure of chronic 1K1C hypertensive rats (13). Increased local concentration of angiotensin II may participate in the maintenance of vascular tone and hypertension. In fact, renin-angiotensin system inhibitors showed significant depressor effects

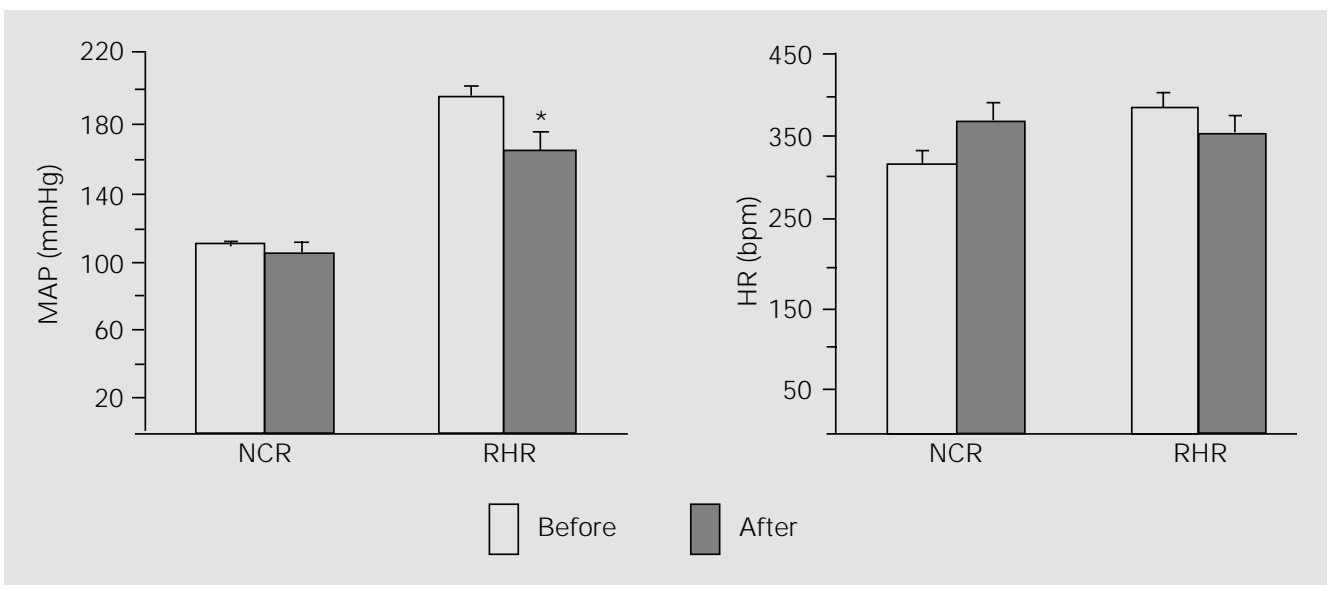

Figure 1 - Mean arterial pressure (MAP) and heart rate (HR) of conscious normotensive control rats (NCR) or chronic $1 \mathrm{~K} 1 \mathrm{C}$ renal hypertensive rats (RHR), before and after acute administration of losartan (10 mg/kg, iv). *P<0.05 compared to before losartan (Student t-test). 
Figure 2 - Baroreflex sensitivity of conscious normotensive control rats (NCR) or chronic $1 \mathrm{~K} 1 \mathrm{C}$ renal hypertensive rats (RHR), determined by mean index and linear regression for bradycardic (A) and tachycardic (B) responses, and by logistic function (C) before (Pre) and after (Post) acute administration of losartan (10 mg/kg, iv). *P<0.05 compared to normotensive rats (Student t-test). AG, Average gain.

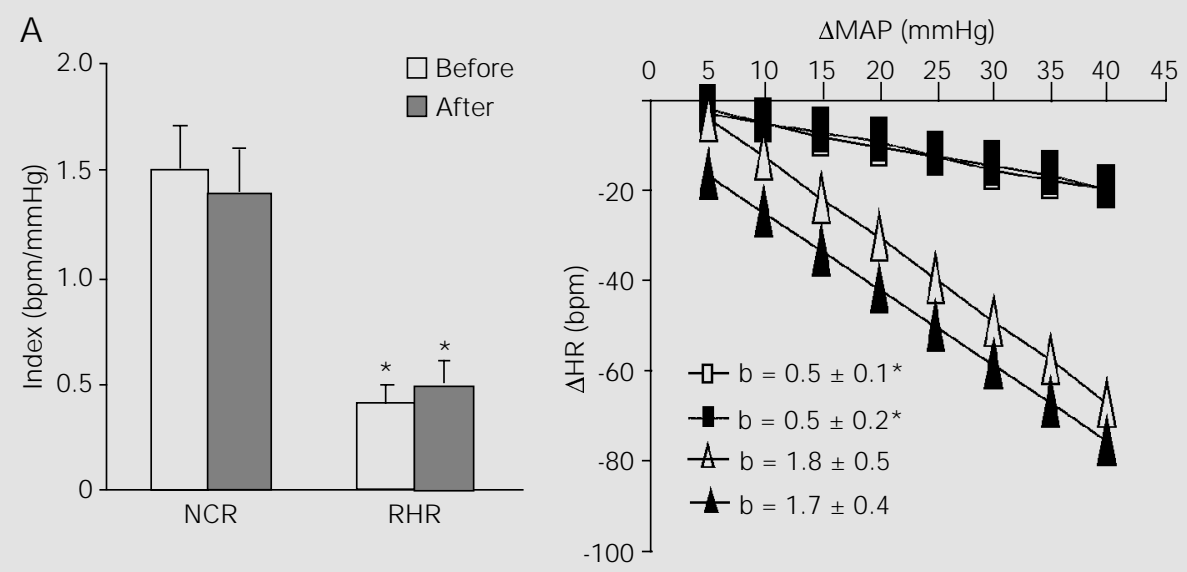

B
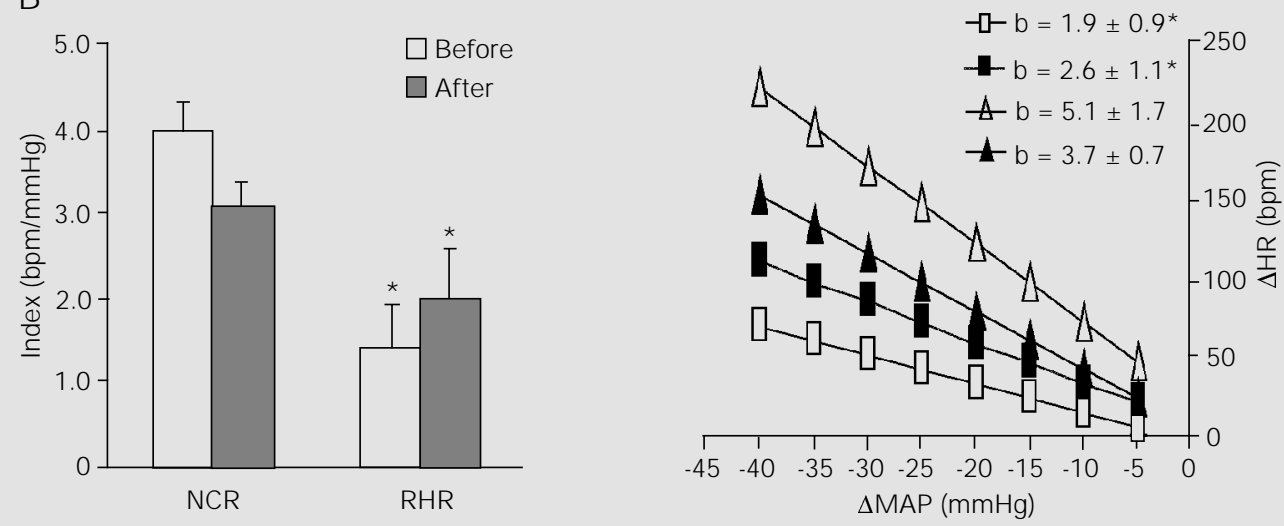

C

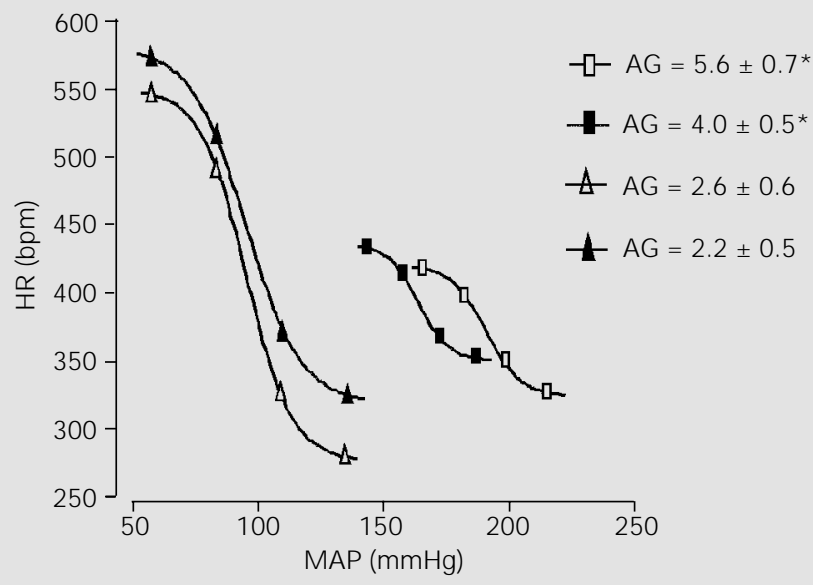

-ㄴ-RHR-Pre

$\triangle$ NCR-Pre 
when vascular renin, but not plasma renin, was high, indicating that angiotensin II generated by renin in vascular tissue exerts a significant pressor effect $(14,15)$. So the hypotensive effect of losartan in $1 \mathrm{~K} 1 \mathrm{C}$ hypertensive rats can be attributed to the inhibition of the AT1 receptor on vascular smooth muscle that reduces vascular tone.

When AT1 is blocked, this effect on vascular tone and cell growth is increased by additional effects of the AT2 receptor when exposed to increased angiotensin II concentrations (16). In fact, it has been demonstrated that AT1 receptor antagonists such as losartan might reduce blood pressure not only by blockade of AT1 receptors, but also through the stimulation of AT2 receptors by excess angiotensin II causing vasodilatation (17). This vasodilatation may be mediated by renal nitric oxide production through stimulation by angiotensin II at the angiotensin AT2 receptor (18).

The present data showed blood pressure reduction and no reversal of the hyposensitivity of the baroreflex by acute losartan treatment. Impairment of reflex bradycardia has been described in several models of chronic hypertension such as renal (1-3), spontaneous (4), and essential hypertension (5), and a possible role for the renin-angiotensin system was always suggested. This assumption was based on the ability of angiotensin II to exert inhibitory influences on baroreceptor reflex control of HR as ob- served in rats (4). The ability of angiotensin II to exert inhibitory influences on baroreceptor reflex control of HR has been observed by several authors $(2,4,11,19)$, but in many of those experiments an increased plasma angiotensin II concentration existed. Indeed, we demonstrated in previous studies that in high-renin hypertension the acute administration of losartan is effective in reversing the depressed baroreceptor reflex bradycardia (11). Chronic administration of losartan also reverses baroreflex tachycardia (18). Moreover, losartan improves the sensitivity of afferent aortic nerve activity (20) in hypertensive coarcted rats during loading and unloading of receptors in the physiological range of pressure changes. Although a great deal of evidence exists showing the role of the renin-angiotensin system in baroreceptor sensitivity, the actual role of the tissue renin-angiotensin system was not considered.

In the present study, losartan reduced blood pressure, but this reduction did not improve the baroreflex control of HR. In fact, in previous studies we demonstrated that in the time frame of the present experiment ( 15 to 45 min after pressure normalization) we could not expect a marked improvement in the hyposensitivity of the peripheral baroreceptors present in this model of hypertension by reducing the level of hypertension.

\section{References}

1. Guo GB \& Abboud FM (1984). Impaired central mediation of the arterial baroreflex in chronic renal hypertension. American J ournal of Physiology, 246: H720-H727.

2. Irigoyen $\mathrm{MC}$, Moreira RD, Moreira ED \& Krieger EM (1991). High-renin renal hypertension depresses the baroreflex control of heart rate and sympathetic activity. In: Kunos G \& Ciriello J (Editors), Central Neural Mechanisms of Blood Pressure Regulation. Birkhauser Boston Inc., Bos- ton, MA, 254-264.

3. Moreira ED, de Oliveira $M \&$ Krieger EM (1988). Impaired baroreflex control of heart rate in high-renin renal hypertension. J ournal of Hypertension, 6: 619-625.

4. Casto R \& Phillips MI (1986). Angiotensin II attenuates baroreflex at nucleus tractus solitarius of rats. American J ournal of Physiology, 250: R193-R198.

5. Sleight $P$ (1989). The relevance of baroreflex mechanisms to the control of ambu- latory and exercise blood pressure in humans. Clinical and Experimental Pharmacology and Physiology, 15 (Suppl): 65-69.

6. Moreira ED, Ida F \& Krieger EM (1990). Reversibility of the baroreceptor hyposensitivity during reversal of hypertension. Hypertension, 15: 791-796.

7. Leenen FHH \& Myers MG (1984). Pressor mechanisms in renovascular hypertensive rats. In: de J ong W (Editor), Handbook of Hypertension. Vol. 4: Experimental and 
Genetic Models of Hypertension. Elsevier Science Publishers B.V., Amsterdam, The Netherlands, 24-80.

8. Dzau VJ \& Pratt RE (1992). Renin-angiotensin system. In: Fozzard HÁ (Editor), The Heart and Cardiovascular System. Raven Press, New York, 1817-1849.

9. Wong PC, Price WA, Chiu AT, Duncia J V, Carini DJ, Wexler RR, Johnson AL \& Timmermans PBMWM (1990). Nonpeptide angiotensin II receptor antagonists. VIII. Characterization of functional antagonism displayed by DuP 753 , an orally active antihypertensive agent. J ournal of Pharmacology and Experimental Therapeutics, 252: 719-725.

10. Wong PC, Price WA, Chiu AT, Duncia J V, Carini DJ, Wexler RR, J ohnson AL \& Timmermans PBMWM (1990). Nonpeptide angiotensin II receptor antagonists. IX. Antihypertensive activity in rats of DuP 753, an orally active antihypertensive agent. J ournal of Pharmacology and Experimental Therapeutics, 252: 726-732.
11. Moreira ED, Ida F, Pires MD \& Krieger EM (1994). DuP 753 is more effective than captopril on baroreceptor function in highrenin hypertension. Hypertension, 23 (Suppl I): I-64-I-67.

12. Farah VMA, Moreira ED, Pires MD, Irigoyen MCC \& Krieger EM (1999). Comparison of three methods for the determination of baroreflex sensitivity in conscious rats. Brazilian J ournal of Medical and Biological Research, 32: 361-369.

13. Leite R \& Salgado COM (1992). Increased vascular formation of angiotensin II in onekidney, one-clip hypertension. Hypertension, 19: 575-581.

14. Swales J D (1979). Arterial wall or plasma renin in hypertension. Clinical Science, 56: 293-298.

15. Thurston $\mathrm{H}$, Swales JD, Bing RF, Hurst BC \& Marks ES (1979). Vascular renin-like activity and blood pressure maintenance in the rat. Hypertension, 1: 643-649.

16. Unger T, Chung O, Csikos T, Culman J, Gallinat S, Gohlke P, Höhle S, Meffert S,
Stoll M, Stroth U \& Zhu YZ (1996). Angiotensin receptors. J ournal of Hypertension, 14 (Suppl 5): S95-S103.

17. Gigante $B$, Piras $O$, De Paolis $P$, Porcellini A, Natale A \& Volpe M (1998). Role of the angiotensin II AT2-subtype receptors in the blood pressure-lowering effect of losartan in salt-restricted rats. J ournal of Hypertension, 16: 2039-2043.

18. Siragy HM \& Carey RM (1997). The subtype 2 (AT2) angiotensin receptor mediates renal production of nitric oxide in conscious rats. J ournal of Clinical Investigation, 100: 264-269.

19. Santos $C M$, Pontieri $V$, Neto $M L \&$ Michelini LC (1995). Losartan improves baroreflex control of heart rate of coarcted hypertensive rats. American J ournal of Physiology, 269: H812-H818.

20. Santos CM, Moreira ED, Krieger EM \& Michelini LC (1998). Chronic AT1 receptor blockade alters aortic nerve activity in hypertension. Hypertension, 31: 973-977. 